\title{
The influence of durability and recycling on life cycle impacts of window frame assemblies
}

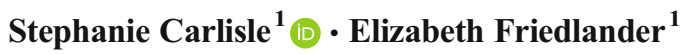

Received: 24 July 2015 / Accepted: 10 March 2016/Published online: 6 April 2016

(C) The Author(s) 2016. This article is published with open access at Springerlink.com

\begin{abstract}
Purpose A set of comparative life cycle assessment case studies were undertaken to explore key issues relating to the environmental impacts of building materials. The case studies explore modeling practice for long-life components by investigating (1) recycled content and end-of-life recycling scenarios and (2) service life and maintenance scenarios. The study uses a window unit frames as the object of comparison, allowing for exploration of multiple materials and assembly techniques. Methods Four window frame types were compared: aluminum, wood, aluminum-clad wood, and unplasticized PVC $(\mathrm{PVCu})$. These used existing product life cycle inventory data which included primary frame material, coatings, weather stripping sealants, but not glazing. The functional unit was a window frame required to produce $1 \mathrm{~m}^{2}$ of visible glazing, with similar thermal performance over a building lifespan of 80 years. The frames were compared using both the end-oflife and recycled content methods for end-of-life scenarios. The models were also tested using custom-use scenarios.

Results and discussion Well-maintained aluminum window frames proved to be the least impactful option across all categories, in large part due to the credits delivered from recycling and expectations of long-life. Wood window frames had the least variability associated with maintenance and durability. The global warming potential (GWP) of a moderately maintained aluminum assembly was found to be $68 \%$ less
\end{abstract}

Responsible editor: Andrea J. Russell-Vaccari

Stephanie Carlisle

scarlisle@kierantimberlake.com

1 KieranTimberlake Research Group, KieranTimberlake, 841 North American St., Philadelphia, PA 19123, USA than PVCu and $50 \%$ less than aluminum-clad wood. Using a long-life scenario, wood windows were found to have a $7 \%$ lower GWP than the long-life scenario for aluminum-clad woods. Moderately and well-maintained aluminum windows require less energy to be produced and maintained over their lifetime than any of the wood scenarios. Expectations of service life proved to be the most important factor in considering environmental impact of frame materials.

Conclusions The research shows significant gaps in available data - such as average realized life expectancies of common building components-while further underscoring that recycling rates are a driving factor in the environmental impact of aluminum building products. A modeling shift from the recycled content method to the end-of-life recycling method should promote goals of material recovery over pursuit of material with high recycled content. Hybrid methods, such as the use of Module D, may bridge the divide between these two approaches by providing due credit for use of recycled material, while supporting a design for recycling ethos. Further research is needed on how design and construction decisions affect collection and recovery rates in practice.

Keywords Aluminum · Buildings $\cdot$ Durability $\cdot$ EoL $\cdot$ LCA . Life cycle methodologies $\cdot$ Maintenance $\cdot \mathrm{PVCu}$.

Recyclability $\cdot$ Recycled content $\cdot$ Service life $\cdot$ Wood $\cdot$ Windows

\section{Introduction}

Collectively, buildings have significant environmental impacts throughout their life cycles, from material production and initial construction through use and eventual demolition and disposal/recycling. In the USA, residential and commercial buildings comprise $70 \%$ of total energy consumption 
(D\&R 2012) and emit $40 \%$ of total $\mathrm{CO}_{2}$ emissions (EIA 2011).

As architects and engineers continue to strive to make buildings less energy intensive to operate, increasing attention is being paid to a broader set of environmental considerations (e.g., resource consumption, presence of chemicals of concern, land use change) and quantitative methods, such as life cycle assessment, capable of capturing the impacts over a building's full life cycle (Bayer et al. 2010; Crawford 2011; Simonen 2014). Increasingly, life cycle assessment (LCA) is being adopted by, or mandated to, architects and engineers during the design process in order to give consideration to environmental impact information during the selection of materials, components, and assemblies (Bayer et al. 2010; AlGhamdi and Bilec 2015). Additionally, in recent years, several green building certification systems have integrated LCA into broader sustainability assessments, supporting the increased awareness and use of the methodology among design practitioners working to evaluate built projects (Ortiz et al. 2009; Optis and Wild 2010; Passer et al. 2012; Al-Ghamdi and Bilec 2015).

LCA in the building sector has primarily focused on two key areas: energy performance of buildings (Optis and Wilde 2010) and building materials (Gustavsson and Sathre 2006). To date, the majority of building material and constructionrelated LCAs have focused either on simplified models of whole buildings (with approximate values for an estimated bill of materials) or on the assessment of isolated building materials (e.g., steel, concrete, flooring, insulation). Complex assemblies composed of numerous materials, such as curtain walling, windows and doors, roofing assemblies, and structural systems, are just beginning to be better understood and modeled through the application of nuanced comparative LCAs.

While comparative LCAs and EPDs have become more readily available for a host of interior products, it remains difficult for architects and designers to evaluate complex, long-life assemblies. Particularly in the early stages of design, when a team is most able to make material selection decisions that will most affect the total environmental impacts of a project, quantitative assessments and comparative studies that connect system/material typologies with detailing and design considerations are particularly lacking. While system performance and durability play a significant role in both life cycle costing and energy modeling, these factors are difficult to study using Environmental Product Declarations (EPDs) and other cradle-to-gate life cycle assessments. Additionally, for many architectural conditions and systems, a design may consider a range of materials that serve similar functions but differ in durability, expected service life, maintenance concerns, and end-of-life options such as material recovery and recycling.
This study uses window frame assemblies as an object of study to explore the role of use phase and end-of-life variables on environmental impacts across a full building life.

\subsection{Durability, maintenance, and expected lifetime}

Generally, questions of maintenance practices and material replacement have been insufficiently addressed in LCA work due to the difficulties associated with quantifying the benefits of physical properties such as durability for building materials (Aktas and Bilec 2012; Liu and Müller 2012; Miller et al. 2015). For windows, questions of durability and material replacement are particularly significant (Andreson et al. 2001). Frame assemblies are composed of a number of materials serving different purposes and subjected to varying stresses and wear. Therefore, the act of window refurbishment and replacement is a meaningful part of the building life cycleand a growing topic of interest for high-performance building design and retrofit.

In a published literature, the majority of LCAs conducted for window frames have focused on the manufacturing and end-of-life impacts as stand-alone products with no specified service life (Sinha and Kutnar 2012; Salazar and Sowlati 2008; Asif et al. 2002, 2007; Citherlet et al. 2000). Or, they have shortened model time frames to 40 or 50 years, so that they do not include significant maintenance or material replacement for some or all of the materials studied (Mösle et al. 2015).

Additionally, most EPDs are cradle-to-gate assessments, which leave out the question of use phase impacts entirely. This trend can, in part, be explained by the difficulty of approximating an accurate service life for window frames - a long-life product whose replacement can hinge on a number of factors, from esthetics to performance to user needs. Although a product manufacturer may wish to provide a set of default scenarios in an EPD from which the building assessor may choose, the number of potential influencing factors on the use phase makes this impractical, due to the large number of combinations of factors related to climate, wear, and maintenance practices. However, when examining material use on buildings that must achieve high-performance standards for 80-100 years, the assumed service life of a component such as window frames does matter, as a single full replacement of an assembly will effectively double the product's life cycle impacts.

While it is indeed difficult to overcome the uncertainty of selecting a single assumed service life for an assembly without fully understanding the building context and maintenance regime (Aktas and Bilec 2012; Minne and Crittenden 2015), comparative LCA facilitates the exploration of this topic through the testing of multiple use scenarios. This approach recognizes that maintenance regimes are project specific, influenced by a range of factors (e.g., building type, location, 
budget, use), and that LCA results will be influenced by assumptions made during the modeling process.

\subsection{End-of-life modeling}

When comparing architectural assemblies composed of different materials, it can be a challenge to assess material recycling along the product life cycle, as discussed in the many papers that approach the issue of allocation in less complex material assemblies through system expansion (Klöpffer 1996; Ekvall and Tillman 1997; Ekvall 2000; Ekvall and Weidema 2004), a practice that adds complexity to both data collection and interpretation (Werner and Richter 2000). In response to increasingly complex products and comparisons, LCA methodology has developed an array of allocation methods (Ekvall and Tillman 1997; Ekvall and Finnveden 2001; Nicholson et al. 2009; EC 2010).

In the building and construction sector, variability in approaches to allocation of recycling credits and end-oflife impacts has posed challenges for cross-material and cross-industry comparisons (SIS 2012; Leroy et al. 2012). This is particularly true for building products that contain recycled content or those that involve material collection and recycling at end of life. Presently, two methods predominate: the recycled content method and the end-of-life recycling method. While the selection of an allocation method has a large impact on model results, there is a general lack of consensus as to which method should be used (Frischknecht 2010; Hammond and Jones 2010; Wardenaar et al. 2012; Huang et al. 2013).

The lack of consensus among LCA practitioners leads to difficulty of interpretation of data results across studies as calculation methods vary. The recycled content approach is particularly difficult to apply in the case of metals such as aluminum, as it requires the precise knowledge of recycled content by mass in an assembly, which is difficult to determine when availability of scrap is variable and scrap is incorporated in production melts with no change in performance properties (Schlesinger 2013; Puga et al. 2009; EAA 2013). For this reason, the endof-life recycling method is preferred within the metal industry (Atherton 2007; Liu and Müller 2012; EAA 2013; PE International 2014) and increasingly used in both building material and whole building life cycle assessment reporting, such as EPDs (SIS 2012; ISO 14040:2006; ISO 14044:2006; ISO 21930:2006). On the other hand, using this method for building materials may be inaccurate, as application of the end-of-life recycling method to buildings requires prediction of reclamation rates and impacts of recycling at the end of life for long product lifetimes (Hammond and Jones 2010).

\section{Goal}

The primary objective of this study is to demonstrate the importance of durability and material replacement in the total life cycle impacts of window frame assemblies. Unlike previous studies, this comparative assessment interrogates multiple maintenance and replacement scenarios in order to test variability of use-phase impacts across a full building lifetime and to more accurately display the design consequences of material selection. The secondary objective of this study is to determine the impact of end-of-life modeling practice on LCA results.

\section{Scope}

\subsection{Functional unit}

This study examines four common types of window frames: aluminum, wood, aluminum-clad wood, and unplasticized PVC (PVCu) casement window frames. In order to compare different material options, data is normalized for material required to produce frames for $1 \mathrm{~m}^{2}$ of visible glazing. Glazing is excluded from the study, as it is assumed to be equivalent across window types.

Each window frame assembly option is considered across a full building lifetime. The lifetime of a building is assumed to be 80 years, in order to represent an average building lifetime while allowing for comparison across studies of various building systems and materials (Preservation Green Lab 2012; US Department of Energy 2010).

To normalize for performance and to assure functional equivalence over the building lifetime, all window assemblies have been designed to yield similar thermal performance $(U$ values between 1.5 and $1.6 \mathrm{~W} / \mathrm{m}^{2} \mathrm{~K}$ ) and visible light transmission. As aluminum has a high thermal conductivity, achieving this level of thermal performance required the selection of a frame with an included inert plastic thermal break. The reference window size for all assemblies is $1.6 \times 1.3 \mathrm{~m}^{2}$ with a visible frame surface of $0.45 \mathrm{~m}^{2}$ in the case of metalclad, $\mathrm{PVCu}$, and wooden frames and $0.48 \mathrm{~m}^{2}$ for the aluminum window (Weidema et al. 2013). Frame quality is expected to be of North American Fenestration Standard (NAFS) performance class R or LC (Fig. 1).

\subsection{Service environment}

The service environment for the purpose of evaluation is assumed to be a rural, non-coastal location. Frames are assumed to be a part of a flush vertical facade. Corrosion and accelerated material fatigue due to high levels of atmospheric pollution, condensation, or salt are considered out of scope for this study. This study assumes perimeter flashing and sealing is 
Fig. 1 Frame types, from left to right: aluminum, wood, aluminum-clad wood, and $\mathrm{PVCu}$
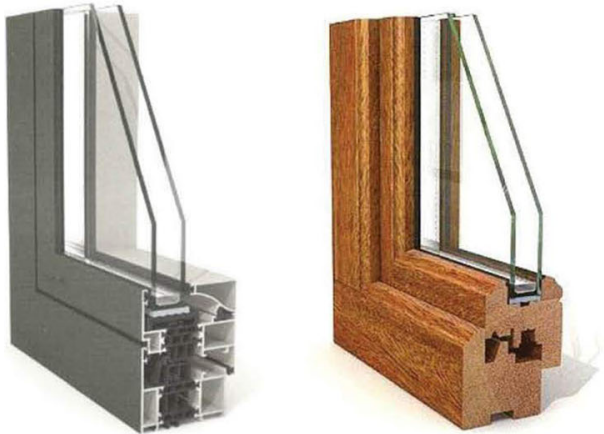

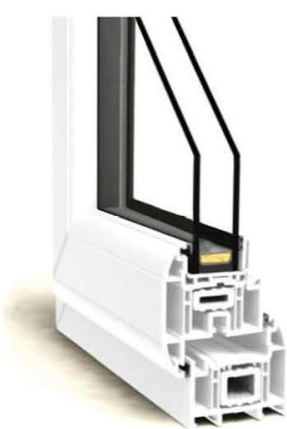

completed with proper workmanship to avoid trapping of water around the perimeter of frame. Equally, it is assumed that common best-practice construction is used for building detailing to prevent galvanic action in the frames containing metal.

\subsection{System boundaries}

Window frame assemblies include primary frame material and all additional materials required for assembly and installation, including gaskets, weather stripping, internal hardware, sealing, coating, and finishing. A $1 \%$ cut-off factor by mass was used, with the exception of known chemicals that have high environmental impacts at low levels. In these cases, a $1 \%$ cut-off was implemented by impact. Human labor, production of the machines for manufacturing, and infrastructure used are outside of the scope of this study. Transportation, both from manufacturing location to construction site and from construction site to disposal or recycling, is assumed to be highly variable and not particularly impactful, but was included according to market data and tested with a standard uncertainty analysis.

Use phase figures are calculated by multiplying the quantities of all material components by the number of installations required over the lifetime of the building. Labor associated with installation and maintenance of window frames is not included in the estimates of use-phase impacts and is considered outside the scope of this study.

All assemblies are modeled using end-of-life disposal scenarios tuned to present construction and demolition waste diversion and recycling rates (Doka 2007; Weidema et al. 2013). In this disposal scenario, several materials are diverted for recycling, including the following: paper $(85 \%)$, glass (94\%), aluminum (90\%), steel (75\%), PET (80\%), and PVC $(20 \%)$. For paper, glass and steel collection rates are based on European averages (Doka 2007). The collection rates for steel are lower than those for aluminum due to the economic inefficiency in collecting the many small steel pieces intermingled with other materials in assemblies. In the case of aluminum and plastics, the rates have been updated from European averages to reflect sector-specific collection rates (IAI 2014; VinylPlus 2014). All remaining materials not diverted for recycling are then modeled using a waste processing typical of European averages, with $88 \%$ of material sent to incineration and $12 \%$ sent to landfill (Weidema et al. 2013). Materials such as wood, for which there is energy generated during incineration, receive a credit for the avoidance of energy generation that they offset as well as the burden for the impacts of the incineration (Figs. 2 and 3).

End-of-life modeling utilizes the end-of-life recycling method as recommended by ISO standards and the ILCD handbook (ILCD 2010, ISO: 21930 2006) except where otherwise noted.

\section{Methods}

\subsection{Data source and quality}

Frame assemblies were created in the SimaPro 8 software using data based on the window frame entries in the Ecoinvent v3 allocation database (Weidema et al. 2013). TRACI 2 v3.01 (Bare 2002) was used for impact assessment of inventory data.

Data on representative window assemblies and construction are based on general product descriptions contained in selection data standards from MasterSpec (ARCOM 2014). This guidance specifically recommends against using PVC resins containing recycled content for performance reasons. Therefore, this study assumes $100 \%$ virgin PVC frames, despite the availability of alternatives in the market. Service life figures and maintenance regimes are drawn from industry guidance available to architects, engineers, and cost estimators including product warranties, life cycle costing databases (RSMeans 2014), and practice (Preservation Green Lab 2012).

Nuanced data on average achieved lifetimes for components of window assemblies does not presently exist. Similarly, a comprehensive database of recycling and collection rates in the USA or Europe across project types is not publically available. For the purpose of this study, end-of-life impacts and credits were modeled using typical waste scenarios and processes from the Ecoinvent v3 database (Weidema 

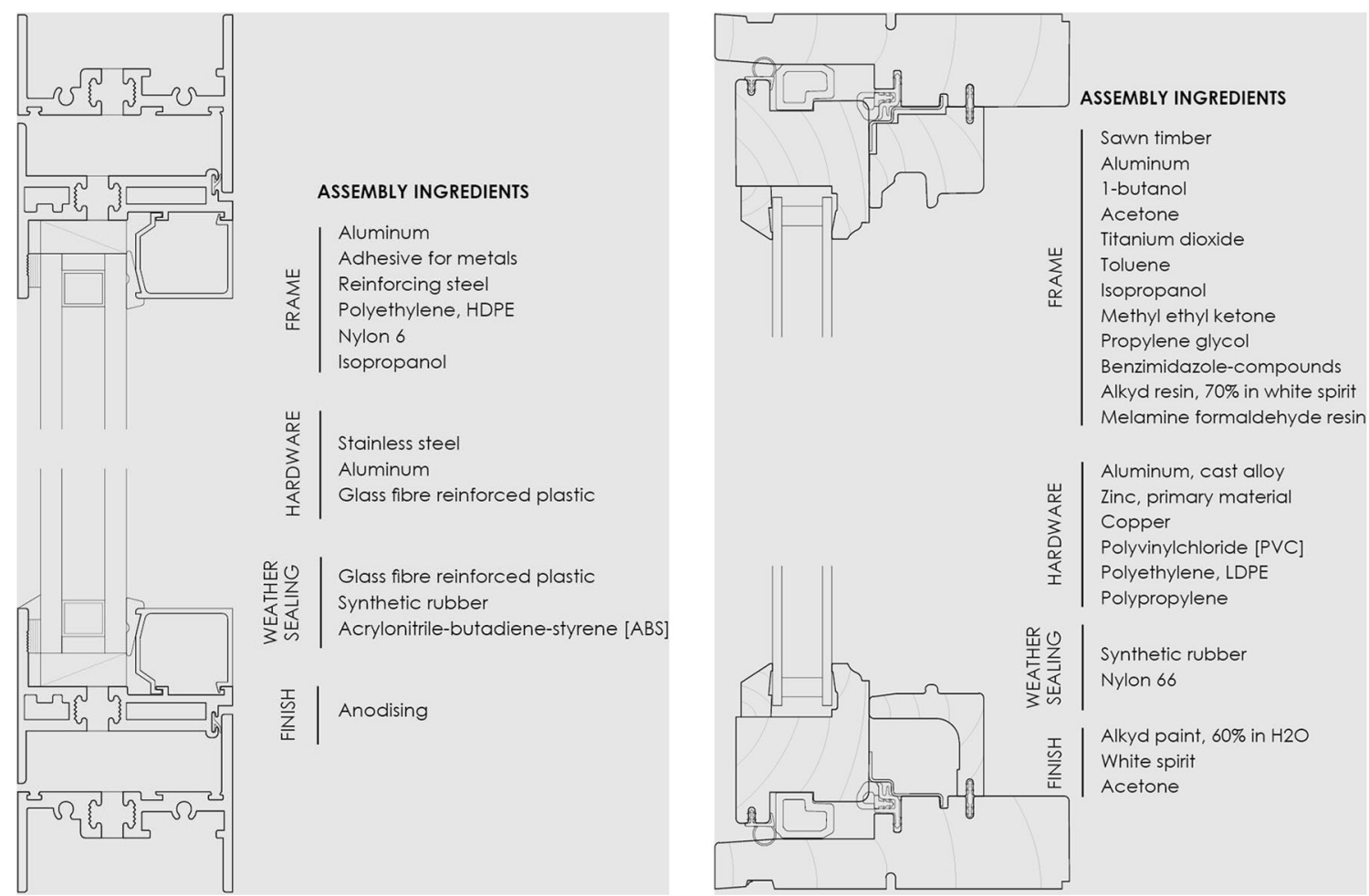

Fig. 2 Section detail and ingredient list: aluminum casement window (left) and wood casement window (right)

et al. 2013), adjusted to reflect the collection and processing of construction and demolition (C\&D) disposal streams (Weidema et al. 2013; CDM 2010; NEWMOA 2009; US
EPA 2009). In the case of aluminum and plastics, collection rates are based on European averages (Doka 2007) and reflect sector-specific collection rates (IAI 2014; VinylPlus 2014).
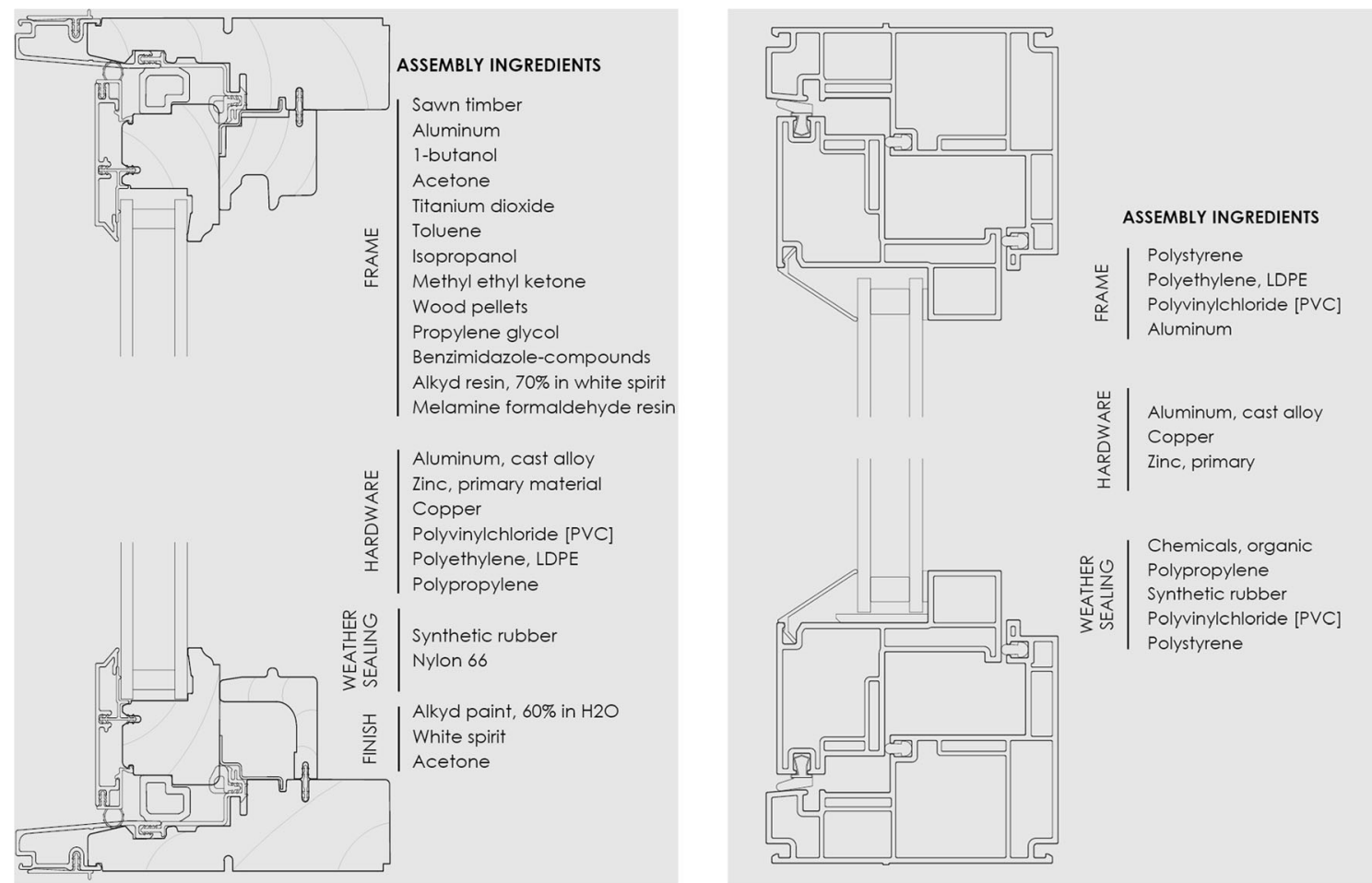

Fig. 3 Section detail and ingredient list: aluminum-clad wood casement window (left) and PVCu casement window (right) 


\subsection{Maintenance model}

The documentation for the original window frame entries in the Ecoinvent v3 database (Weidema et al. 2013) differentiates specific quantities of metals, plastics, and composite materials used for production of frames, fittings, sealing, and coating. For the purposes of this study, custom assemblies were created to represent "recoating," "resealing," and "replacement of hardware" for each frame type in order to generate nuanced maintenance and replacement regimes. Likewise, waste scenarios were adjusted from the Ecoinvent v3 database to represent scenarios for disposal of materials such as replacement hardware, fittings, and weather proofing applied during the use stage for the purposes of maintenance and replacement.

The model uses an incremental allocation methodology to account for periodic component replacements associated with functional failure and wear rather than a pre-emptive, timed replacement of whole frames across a building. This methodology is consistent with an approach to maintenance scenarios that maintains functional equivalence across assembly types and practices based on consistent window performance throughout the full building life cycle, rather than assuming a full replacement of every window in a building on a timed cycle.

Rather than choosing a single estimated service life for each frame assembly, three use scenarios were developed that seek to represent a range of potentials grounded in the material attributes and typical maintenance practices for each window frame assembly. The specifics of this modeling methodology are outlined in Table 1 for each frame type.

Replacement cycle length is based on best-practice maintenance and repair by frame type (RSMeans 2014). Of particular note is the difference in expected service life of weather sealing between the aluminum frames and other frame types. This is due to a difference in weather stripping type by frame material: aluminum frames use a solid precision seal that creates a tight fit with minimal deformity of the seal material, whereas the other frame types use a larger, compressive-type hollow-bulb seal that experiences more movement, wear, and deformity in typical window use.

Scenario 1 It represents the most conservative estimate of window life; it assumes that no significant repair or replacement activities are conducted and that the entire frame assembly is disposed of or recycled and replaced at the end of a typical manufacturer warranty. While this is not reflective of actual building maintenance practices, it reflects assumptions common to many existing LCA models for building products.

Scenario 2 It describes a basic maintenance regime in which a typical building manager or owner follows commonly prescribed maintenance practices aimed at reaching a longer lifespan for the window while maintaining a high level of window performance, as described in Table 1.

Scenario 3 It describes a high-maintenance regime in which a building manager or owner follows best practices aimed at extending the lifespan of a highquality window through regular and frequent maintenance practices, as described in Table 1. As aluminum-clad wood and $\mathrm{PVCu}$ window frames are intended to be maintenance-free products with factory-finished surfaces, the protective

Table 1 Maintenance activities for aluminum, wood, aluminum-clad wood, and PVCu window frames

\begin{tabular}{|c|c|c|c|}
\hline & $\begin{array}{l}\text { Scenario 1: warranty period, } \\
\text { little to no maintenance }\end{array}$ & $\begin{array}{l}\text { Scenario 2: low maintenance, } \\
\text { shorter life }\end{array}$ & Scenario 3: high maintenance, longer life \\
\hline Anodized aluminum & 25 years: full frame replacement & $\begin{array}{l}\text { No cleaning of frames } \\
20 \text { years: replace weather sealing } \\
2 \% / \text { year: replace hardware } \\
60 \text { years: full frame replacement }\end{array}$ & $\begin{array}{l}\text { Annual cleaning of frames } \\
20 \text { years: replace weather sealing } \\
2 \% / \text { year: replace hardware } \\
+80 \text { years: full frame replacement }\end{array}$ \\
\hline Painted wood & 20 years: full frame replacement & $\begin{array}{l}12 \text { years: repaint when coatings have failed } \\
15 \text { years: replace weather sealing } \\
2 \% / \text { year: replace hardware } \\
30 \text { years: full frame replacement }\end{array}$ & $\begin{array}{l}8 \text { years: repaint and treat wood on regular } \\
\text { basis to prevent failure } \\
15 \text { years: replace weather sealing } \\
2 \% / \text { year: replace hardware } \\
+80 \text { years: full frame replacement }\end{array}$ \\
\hline $\begin{array}{l}\text { Aluminum-clad } \\
\text { wood }\end{array}$ & 20 years: full frame replacement & $\begin{array}{l}\text { No refinishing } \\
15 \text { years: replace weather sealing } \\
2 \% / \text { year: replace hardware } \\
30 \text { years: full frame replacement }\end{array}$ & $\begin{array}{l}\text { Not viable due to inability to reinforce } \\
\text { factory-sealed joint between materials } \\
\text { with additional maintenance }\end{array}$ \\
\hline $\mathrm{PVCu}$ & 20 years: full frame replacement & $\begin{array}{l}\text { No refinishing } \\
15 \text { years: replace weather sealing } \\
2 \% / \text { year: replace hardware } \\
30 \text { years: full frame replacement }\end{array}$ & $\begin{array}{l}\text { Not viable due to inability to reapply or prolong } \\
\text { lifespan of UV-inhibiting coating that protects } \\
\text { primary material }\end{array}$ \\
\hline
\end{tabular}


finishes are expected to degrade over time and cannot be renewed through additional maintenance, leading to base material failure. In the case of aluminum-clad windows, this failure occurs as joints in the aluminum facings open, allowing moisture penetration to the underlying wood that leads to rot. In $\mathrm{PVCu}$ windows, the UVinhibiting coating breaks down, causing the PVC to become brittle and crack.

End-of-life modeling utilizes the end-of-life recycling method as recommended by ISO standards and the ILCD handbook (ILCD 2010, ISO: 21930 2006), as described in Section 4.3.

\subsection{Recycling/end-of-life model}

Building materials have complex life cycles, making use of recycled content during manufacturing and also providing materials available for recycling at the end of a product or full building's life. The second model in this study explores the methodological choices available to LCA practitioners when considering both the presence of recycled content in window frame assemblies and also end-of-life scenarios that include material recovery and recycling.

Two choices predominate recycling allocation methodology for recyclable building component models, differentiated by the location of the system boundary. The end-of-life recycling method counts full present recycling potential of a product at its end of life, providing credits for creating recycled content that can offset the use of virgin material in the next product life. This methodology is recommended by the ILCD handbook and ISO standards for materials such as steel and aluminum, whose inherent properties are not altered during recycling.

The recycled content method counts only the proportion of virgin material and recycled content directly contained in a product. This approach is particularly advantageous for products such as wood or mineral products which have high recycled content but are often down-cycled or cannot be reused at end of life. The recycled content method is recommended by several national standards, including the European standard EN15804. While EN15804 primarily uses the recycled content approach, it has also adopted the use of Module D, a possibility for declaring the potential loads and benefits of recycling for a following product system, beyond the boundary of the product system under study. The use of Module D is recommended for long life materials and metals in particular (Leroy et al. 2012), though the method presents challenges for multi-material comparisons.

Each modeling practice is internally consistent, but represents a different view of the relationship between primary and recycled material by focusing either on the recycled content going into the product stream or the recovered material coming out (Frischknect 2010), as described in Table 2. This methodological focus affects the environmental impact results of a study, influencing recommendations for policy and decisionmaking.

For these scenarios, windows are assumed to follow the basic maintenance regime from the previous maintenance study, while the recycling credit allocation method is varied.

Scenario 1 It uses the recycled content method to allocate the full burden of production to the first life of the material and only considers the impacts of the recycling process for the share of the product that is from recycled sources. In this scenario, aluminum assemblies are modeled with a mix of $67 \%$ primary aluminum and $33 \%$ secondary aluminum from a mix of old and new scrap (EAA 2013). Scenario 1 does not utilize Module D.

Scenario 2 It employs the end-of-life recycling method, giving credit for future recyclability and reclamation by passing the environmental impacts of the initial production to subsequent uses for materials that can be recycled. This gives the credit for recycling to the product of study for avoiding the impacts that would have been associated with a future product made of entirely virgin material, using the material recycling rates described in Section 3.3 of this paper. In this methodology, the specific recycled content of the product is not measured, as this would constitute double counting.

\section{Results and discussion}

\subsection{Results of maintenance model}

Differences between use scenarios within each material indicate that assumptions regarding durability and length of useable life assumed for window frame assemblies are significant for every material and should be the subject of further research. For aluminum frames, there is a $52 \%$ decrease in the calculated global warming potential and a $45 \%$ decrease in calculated fossil fuel depletion between Scenario 1 and Scenario 3. Studies of aluminum window frames using warranty periods as a means of estimating service life may therefore be approximately doubling their impact estimates when compared to the expectations for building products that are well-maintained (Fig. 4).

For wood frames, there was a $13 \%$ difference between assessments of global warming potential and a $9 \%$ difference in eutrophication impacts between Scenario 1 and Scenario 3. 
Table 2 Recycling credit allocation method comparison

\begin{tabular}{|c|c|c|}
\hline Name of approach & Scenario 1: recycled content method & Scenario 2: end of life recycling method \\
\hline Alternate names & Cut-off method. & Avoided burden method. \\
\hline Key indicator of environmental impact & Recycled content. & Recycling rate at end of life. \\
\hline System boundary & $\begin{array}{l}\text { Cut-off rule applied on recycled materials exiting } \\
\text { the system (analysis looks only at the single product use). }\end{array}$ & Includes impacts of the recycling processes. \\
\hline Who gets the benefits? & $\begin{array}{l}\text { Recycling benefits given to the product using recycled } \\
\text { materials. }\end{array}$ & $\begin{array}{l}\text { Recycling benefits given to the product } \\
\text { providing material for recycling. }\end{array}$ \\
\hline Who carries the burden? & $\begin{array}{l}\text { First use of the material receives the burden of materials } \\
\text { used (primary or recycled; recycled materials do not } \\
\text { carry energy or process burdens), and burden of input } \\
\text { decreases as more recycled content is used. }\end{array}$ & $\begin{array}{l}\text { First use of the material receives credit } \\
\text { for full present recycling potential, } \\
\text { avoiding demand for future primary } \\
\text { material; recycled materials carry } \\
\text { impacts for energy and process } \\
\text { of recycling. }\end{array}$ \\
\hline Indications for policy & Promotes the consumption/use of recycled materials. & $\begin{array}{l}\text { Promotes the production/preservation } \\
\text { of recyclable materials. }\end{array}$ \\
\hline
\end{tabular}

This reveals that for wood, a higher proportion of such impacts is tied to maintenance activities such as painting and refinishing rather than the initial manufacturing, production, or disposal of the base materials. While these environmental savings of increased maintenance are smaller than those for aluminum, there are also economic and labor savings that support the higher maintenance regime.

Although there is no possibility for a high-maintenance option for either PVCu or aluminum-clad wood frames due to material limitations, both still demonstrate benefits in using models assuming maintenance activity to prolong the life of the frame assembly beyond the warranty period, as shown by the differences between Scenarios 1 and 2 .

In addition to the nuances of maintaining aluminum-clad wood window frames over long life spans, end-of-life expectations also contain assumptions regarding demolition practice and material processing. The end-of-life disposal scenario for the aluminum-clad frame assumes that the metal cladding could be stripped from the wooden base material and recycled at a typical diversion rate for aluminum products. However, many of the impacts from the full assembly are tied to the lamination of the materials and the manufacturing of the wooden component of the frame, all of which would be sent to landfill or incineration upon disposal, yielding higher environmental impacts than for the aluminum-only frame assembly.

Results across material types show that the cradle-to-grave impacts of aluminum window frame assemblies are less than those of the other material options in all environmental impact categories when considered for the full building lifespan. Specifically, the global warming potential for a moderately maintained aluminum window assembly is $68 \%$ less than the best-case scenario for PVC and $50 \%$ less than the bestcase scenario for aluminum-clad wood. When considering fossil fuel depletion impacts, moderately and well- maintained aluminum windows (Scenarios 2 and 3 ) required less energy to produce and maintain over their lifetime than any of the wood scenarios. Well-maintained wood windows have $7 \%$ less global warming impact than the best-case aluminum-clad wood option and have a nearly $30 \%$ lower impact when the warranty period is used as an estimation of the length of the assembly's lifespan. In large part, this low environmental impact of aluminum frame assemblies can be attributed to the credits delivered at end of life from recycling aluminum into future building products.

While this model was built to measure the importance of durability and maintenance in the use stage of the life cycle, it also makes clear that material reclamation and recycling at end of life is the most significant contributor to reducing the embodied environmental burdens of window frame products. Aluminum frames in particular are adversely affected when life cycle stages are simplified, excluding the benefits associated with durability, low maintenance requirements, or end of life (EAA 2013). The very attributes cited in several existing studies (Sinha and Kutnar 2012; Asif et al. 2007) as contributing to the high impacts of initial frame production contribute to decreased impacts during the product life cycle, especially when end of life recycling is considered.

\subsection{Results of recycling/end-of-life model}

The results of this study support previous authors' emphasis (e.g., Atherton 2007) on the relative importance of recycling credit allocation methods for metals. Aluminum saw a reduction of $51,42,39$, and $38 \%$ in eutrophication, ozone depletion, acidification, and global warming potential, respectively, when the allocation method switched from the recycled content method to the end-of-life method. For metals, the reduction in impacts is due to the credits associated with the reduction of demand for primary material processing, the stage in 
SCENARIO 1: WARRANTY SERVICE LIFE

SCENARIO 2: BASIC MAINTENANCE

SCENARIO 3: HIGH MAINTENANCE

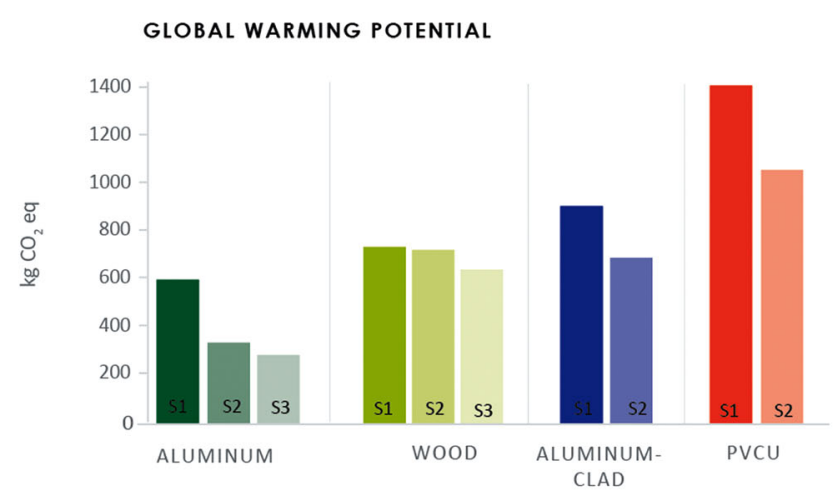

OZONE DEPLETION

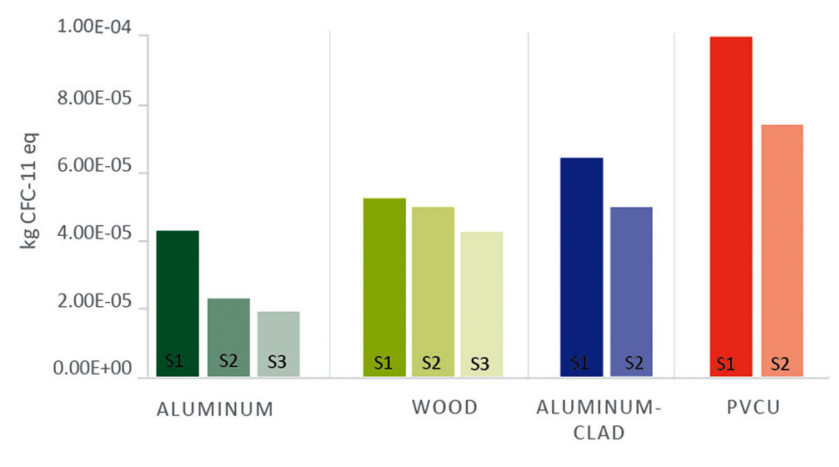

SMOG FORMATION

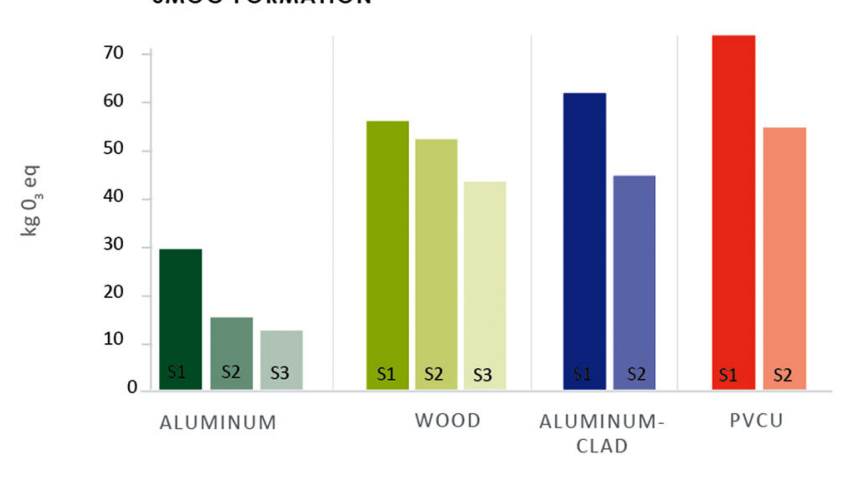

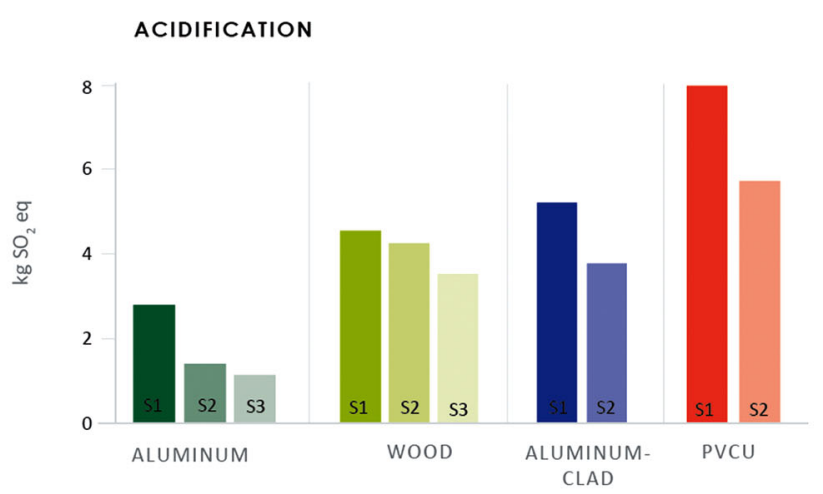

EUTROPHICATION

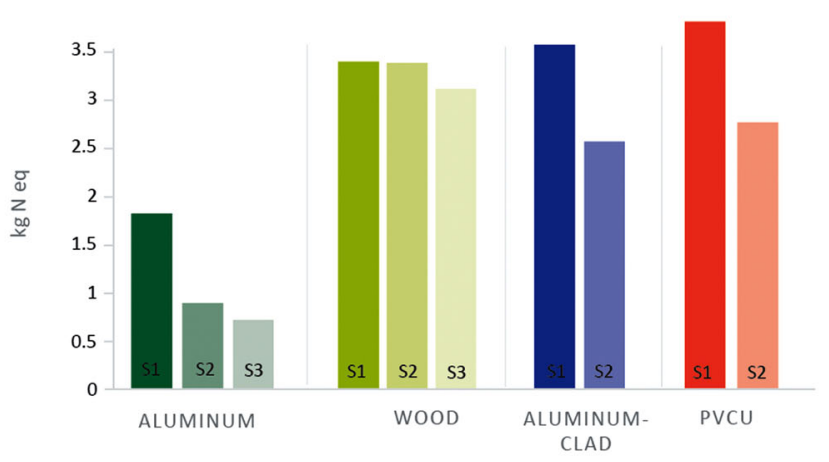

FOSSIL FUEL DEPLETION

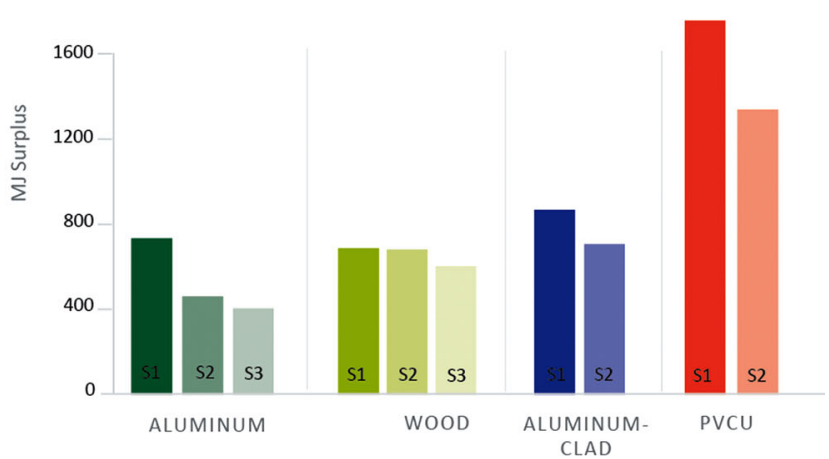

Fig. 4 LCA results for each of the window assemblies and use scenarios across TRACI 2.1 impact categories. Scenario 3 was not a viable option for clad wood or PVC and is therefore not represented

the metal life cycle associated with the largest environmental impacts (Fig. 5).

Similar improvements are seen for aluminum-clad wood frames. This is most likely due to the dramatic difference in environmental impacts for the aluminum cladding of the frame, which experiences the same benefits of environmental impact reduction as the primarily aluminum frame.

$\mathrm{PVCu}$ was the only material to have greater impacts across all categories when the end-of-life method was used. In particular, PVCu increased in the fossil fuel and ozone depletion categories by 59 and $40 \%$, respectively. The poor results for PVCu windows using the end-of-life method can be attributed to the current low recycling rates for plastics, coupled with potential material integrity loss in recycling, but an increase in waste diversion and material reclamation for plastics in construction would decrease their relative impacts. Sensitivity analysis shows that increasing recycling rates results in a linear decrease in most environmental impacts. 
SCENARIO 1: RECYCLED CONTENT

SCENARIO 2: END OF LIFE

GLOBAL WARMING POTENTIAL

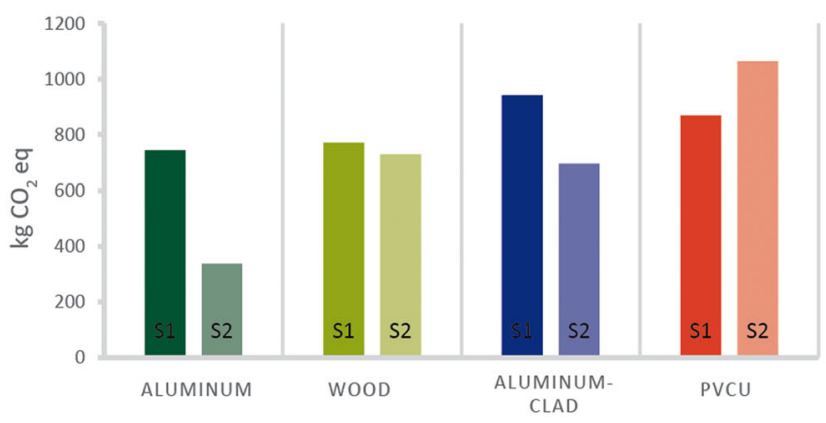

OZONE DEPLEIION

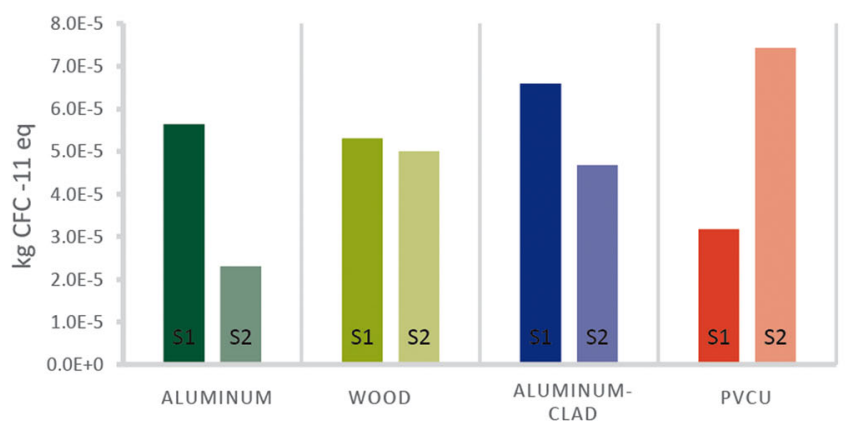

SMOG FORMATION

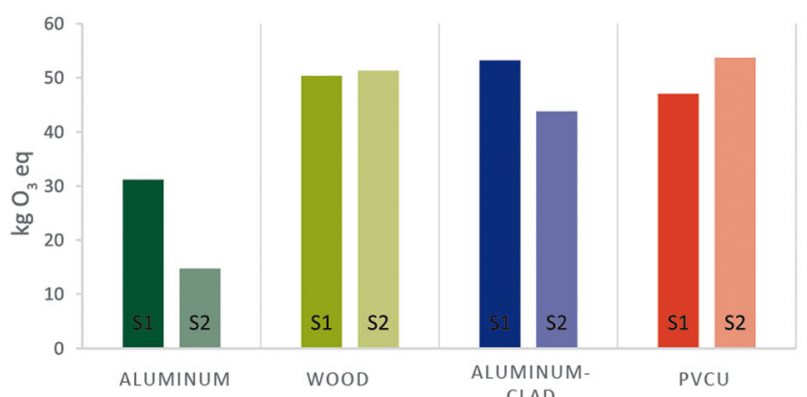

ACIDIFICATION

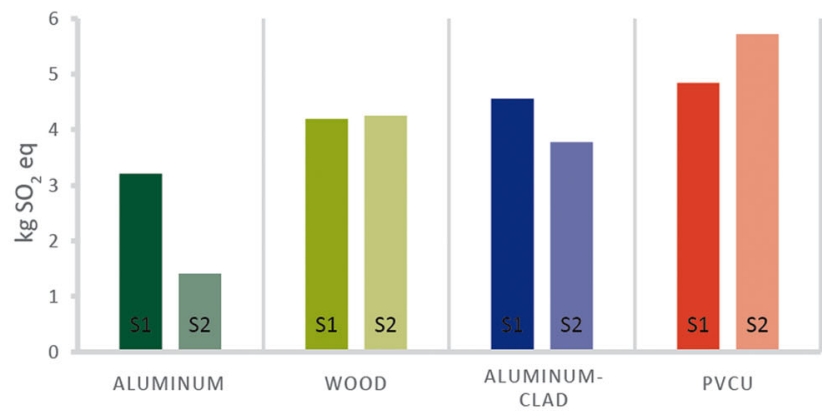

EUTROPHICATION

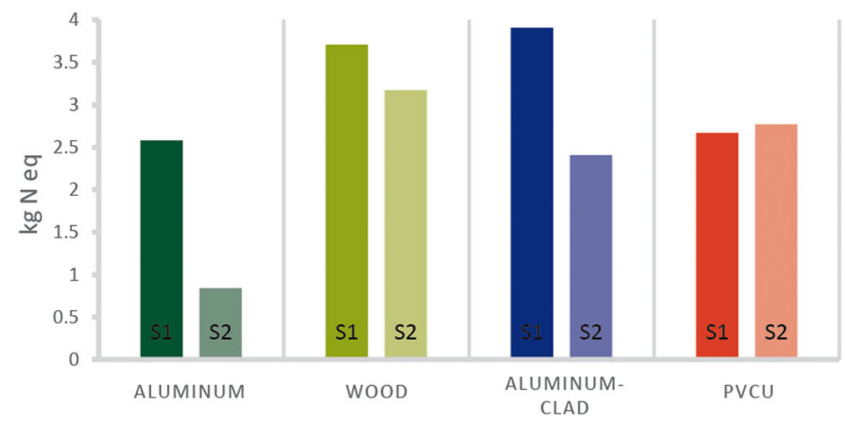

FOSSIL FUEL DEPLETION

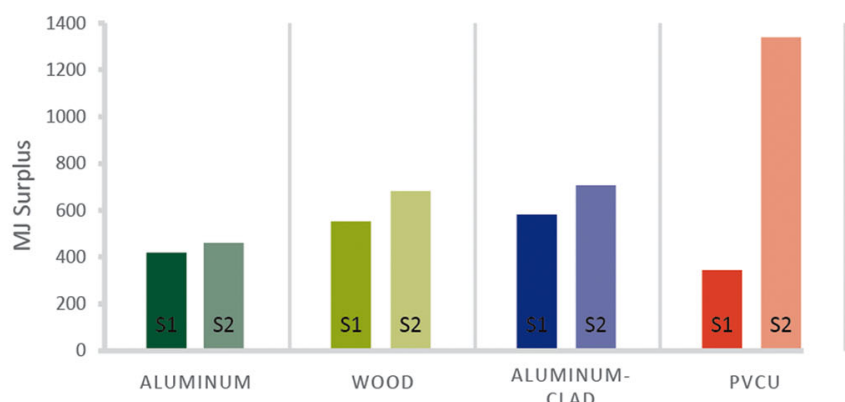

Fig. 5 LCA results for each of the window assemblies and allocation scenarios across TRACI 2.1 impact categories

Although most of the embodied impact categories decreased for the majority of material assemblies using the end-of-life method, each assembly had an increase in fossil fuel depletion. Aluminum increased the least (5\%), with aluminum-clad wood and wood frames having an equivalent increase (10\%), and PVCu increasing the most (59 \%). This increase can be attributed to the inclusion of end-of-life processes and impacts for recycling, including the transportation of materials, such as to and from the recycling plant.

The results clearly indicate that the choice of allocation method has a significant impact on the magnitude of environmental impacts the model associates with the material in question, influencing recommendations for policy and decision-making based on the results. Using the recycled content method (Scenario 1), greater focus is placed on the avoidance of virgin material, as manufacturing and construction inputs make up a large portion of the overall environmental impacts. While this creates positive demand for materials with a high potential recycled content such as $\mathrm{PVCu}$, for metals such as aluminum, this creates further demand for recycled content that has already outpaced the available supply of recycled material (Bertram et al. 2009; Rombach 2013). For materials such as $\mathrm{PVCu}$, an increased desire for recycled content may indeed increase competitiveness and recycling rates 
in circumstances where material recycling does not provide the same financial savings to manufacturers inherent in metal manufacturing.

Using the end-of-life recycling method (Scenario 2), greater focus is placed on material recovery at the end of product use, as materials receive credit for being able to replace virgin material in their next use. The system understanding highlighted in the end-of-life recycling method is particularly beneficial for the metal market, as it may lead to increased efforts to promote material reclamation and recycling pathways in order to reduce environmental impacts (Atherton 2007). While metals in $C \& D$ waste streams already have very high achieved collection and recycling rates in practice due to the high market value of scrap, the use of end-of-life method for plastics may potentially serve as a driver for increasing collection and recycling rates that are presently low in the industry.

Hybrid methods, such as the use of Module D, may bridge the divide between these two approaches. Module D encourages avoidance of virgin material use when possible by providing due credit for the use of recycled material, encouraging behaviors similar to those promoted by the recycled content approach. However, the hybrid method also supports a design for recycling ethos similar to the end-of-life recycling method for materials that have efficient recycling processes but presently have low recycling and reclamation rates. Further research is needed on how design and construction decisions affect collection and recovery rates in practice.

\section{Conclusions}

In this study, four window unit frame assemblies were studied using a series of comparative LCA models examining the relevance of material replacement/maintenance and end of life. For all four window frame types, the choice of service life and the assumed replacement rates of materials affected the final impact results when window frame assemblies were assessed over the full life of a building. Existing LCAs of building materials and assemblies rely heavily on estimates for building lifetime; product service life and maintenance practices and in the absence of available data or applied experience choices are often made arbitrarily and without documentation or justification. The results of this study indicate that such model assumptions are significant and warrant further consideration, both during model creation and interpretation of results.

The results also suggest that the treatment of material recycling and end-of-life processes are important considerations for a range of building materials, including metals, plastics, and wood products. Despite the high embodied impacts of primary aluminum manufacturing, when material recycling and durability are taken into consideration, total environmental impacts of aluminum window frames were consistently lower than wood or PVCu. Models that use short-time frames (less than 60 years) or fail to take material replacement into account misrepresent the full life cycle impacts. Accurate and definitive predictions of durability are challenging as they rely on a range of context- and designspecific factors. Local climate, installation quality, architectural detailing, occupant behavior, and owner expectations can have significant effects on the actual lifespan of a product or assembly when installed in a real building. Although outside of the scope of this study, further research into the importance of different site and context variables - e.g., coastal environments, de-icing regimes - against the range of detailing options - e.g., frame coatings, recession depth of windowscould prove to be significant in providing additional insight when comparing frame types and may influence the resulting recommendation.

While increased data on realized product lifespans will help in creating more grounded estimates, project-specific factors will always drive individual cases, making it difficult to clearly and consistently identify a typical building for use in modeling. Moreover, for long-life materials used in facades or structural elements, the lifespan of the building itself may be the most important unknown factor.

Maintenance regimes and replacement rates used in model scenarios in this study should not be taken as static or definitive figures, but aim to show the range of possible model results and provide some indication of the relative importance of design decisions. Static assessments, such as those often conducted for environmental product declarations or certification purposes, rarely take a range of potential scenarios into account and pose challenges in terms of extrapolating findings to a specific building project. Comparative LCA results can be of value to architects and building owners, influencing the design and management of buildings, if models are crafted in a manner that reflects realistic behavior, particularly across the use phase.

LCA tools such as Tally® and Athena Impact Estimator are making it easier for architects and engineers to conduct robust comparative Life Cycle Assessments of full buildings and design options. Still, greater awareness of methodological factors such as the treatment of end-of-life impacts, recycled content, and expected service life/replacement rates is essential for appropriate interpretation of results, for extrapolation across projects, and for other forms of applied research.

Acknowledgments This research was funded in part through a grant by the International Aluminium Association under the Towards Sustainable Cities Project. The authors would like to thank our research partners on that project: Michael Stacey, Michael Ramwell, and Billie Faircloth for comments, edits, and critique. We also thank Chris Bayliss and Marlen Bertram of the International Aluminium Institute (IAI) as well as members of the EAA Buildings and Transport Groups for data, critique, and support in this research. The views and ideas expressed herein are solely of the authors and do not represent the ideas of funding agencies in any form. 
Open Access This article is distributed under the terms of the Creative Commons Attribution 4.0 International License (http:// creativecommons.org/licenses/by/4.0/), which permits unrestricted use, distribution, and reproduction in any medium, provided you give appropriate credit to the original author(s) and the source, provide a link to the Creative Commons license, and indicate if changes were made.

\section{References}

Aktas CB, Bilec MM (2012) Impact of lifetime on US residential building LCA results. Int J Life Cycle Assess 17(3):337-349

Al-Ghamdi SG, Bilec MM (2015) Life-cycle thinking and the LEED rating system: global perspective on building energy use and environmental impacts. Environ Sci Technol 49(7):4048-4056

Andresen I, Thyholt M, Geissler S, Rappl B (2001) Sustainable use of aluminum in buildings. SINTEF Report STF22 A 15126 (2001)

ARCOM (2014) MasterSpec architectural specifications database

Asif M, Davidson A, Muneer T (2002) Life cycle analysis of window materials - a comparative assessment.' CIBSE National Technical Conference, London. June 182002

Asif M, Muneer T, Kelley R (2007) Life cycle assessment: a case study of a dwelling home in Scotland. Build Environ 42:1391-1394

Atherton J (2007) Declaration by the metals industry on recycling principles. Int J Life Cycle Assess 12(1):59-60

Bare JC (2002) Developing a consistent decision-making framework by using the US EPA's TRACI. In American Institute of Chemical Engineers Symposium. http://www.epa.gov/nrmrl/std/traci/ aiche2002paper.pdf

Bayer C, Gamble M, Gentry R, Joshi S (2010) AIA guide to building life cycle assessment in practice. The American Institute of Architects, Washington DC. http://www.aia.org/aiaucmp/groups/aia/ documents/pdf/aiab082942.pdf

Bertram M, Martchek KJ, Rombach G (2009) Material flow analysis in the aluminum industry. J Ind Ecol 13(5):650-654

CDM (2010) Chicago waste diversion study. (Report, Chicago Department of Environment). http://www.cityofchicago.org/dam/ city/depts/doe/general/RecyclingAndWasteMgmt_PDFs/ WasteAndDiversionStudy/WasteDiversionStudyReport2.pdf

Citherlet S, di Guglielmo F, Gay J (2000) Window and advanced glazing systems life cycle assessment. Energy Buildings 32(3):225-234

Crawford RH (2011) Life cycle assessment in the built environment. Spon Press, London

D\&R International (2012) 2011 buildings energy data book. US department of energy: energy efficiency \& renewable energy pp 1-6

Doka G (2007) Life cycle inventories of waste treatment services.' Ecoinvent report no. 13, Swiss Centre for Life Cycle Inventories, Dübendorf

EAA (2013) Aluminium recycling in LCA. European Aluminium Association, Brussels

Ekvall T (2000) A market based approach to allocation at open loop recycling. Resour Conserv Recycl 29:91-109

Ekvall T, Finnveden G (2001) Allocation in ISO 14041-a critical review. J Clean Prod 9(3):197-208

Ekvall T, Tillman AM (1997) Open-loop recycling: criteria for allocation procedures. Int J Life Cycle Assess 2(3):155-162

Ekvall T, Weidema B (2004) System boundaries and input data in consequential life cycle inventory analysis. Int Life Cycle Assess 9(3): $161-171$

SIS (2012) SS-EN 15804:2012 Sustainability of construction worksenvironmental product declarations - core roles for the product category of construction products. Swedish Standards Institute, Stockholm
Energy Information Administration (2011) Emissions of greenhouse gases in the United States 2009. US Department of Energy: 22

European Commission-Joint Research Centre-Institute for Environment and Sustainability (2010) International Reference Life Cycle Data System (ILCD) Handbook - General guide for life cycle assessment-Detailed guidance. First edition March 2010. EUR 24708 EN. Luxembourg. Publications Office of the European Union

Frischknecht R (2010) LCI modelling approaches applied on recycling of materials in view of environmental sustainability, risk perception and eco-efficiency. Int J Life Cycle Assess 15(7):666-671

Gustavsson L, Sathre R (2006) Variability in energy and carbon dioxide balances of wood and concrete building materials. Build Environ 41(7):940-951

Hammond G, Jones C (2010) Inventory of Carbon \& Energy (ICE). University of Bath, Bath, Annex a: methodologies for recycling

Huang Y, Spray A, Parry T (2013) Sensitivity analysis of methodological choices in road pavement LCA. Int J Life Cycle Assess 18(1):93101

IAI (2014) Global mass flow model. IAI, London, UK http://www.worldaluminium.org/publications/tagged/mass\%20flow\%20model/

ICLD (2010) ILCD handbook - general guide on LCA, Institute for environment and sustainability, European Commission, JRC. http://lct. jrc.ec.europa.eu

ISO 14040:2006 (2006) Environmental management: life cycle assessment: principles and framework (ISO, 2006)

ISO 14044:2006 (2006) Environmental management—life cycle assessment - requirements and guidelines (ISO, 2006)

ISO 21930:2006 (2006) Sustainability in building construction - environmental declaration of building products (ISO, 2006)

Klöpffer W (1996) Allocation rule for open-loop recycling in life cycle assessment. Int J Life Cycle Assess 1(1):27-31

Leroy C, Thomas JS, Avery N, Bollen J, Tikana L (2012) Tackling recycling aspects in EN15804.' International symposium on life cycle assessment and construction, Ed. A. Ventura and C. de la Roche. http:/www.rilem.org/gene/main.php?base=500218\&id publication $=415 \&$ id_papier $=7985$

Liu G, Müller D (2012) Addressing sustainability in the aluminium industry: a critical review of life cycle assessments. J Clean Prod 35: 108-117

Miller SA, Srubar WV, Billington SL, Lepech MD (2015) Integrating durability-based service-life predictions with environmental impact assessments of natural fiber-reinforced composite materials. Resour Conserv Recycl 99:72-83

Minne E, Crittenden JC (2015) Impact of maintenance on life cycle impact and cost assessment for residential flooring options. Int $\mathrm{J}$ Life Cycle Assess 20:36-45

Mösle P, Gama RO, Haun T, Fauth J (2015) Sustainability assessment of windows and curtain walls. (Report, European Aluminium Association, 2015)http://www.dreso.com/uploads/tx_templavoila/ Drees_Sommer_Fassadenstudie_2015.pdf

NEWMOA (2009) Construction and demolition waste management in the northeast in 2006, Northeast waste management officials' as sociation.http://www.newmoa.org/solidwaste/ CDReport2006DataFinalJune302009.pdf

Nicholson AL, Olivetti EA, Gregory JR, Field FR, Kirchain RE (2009) End-of-life LCA allocation methods: open loop recycling impacts on robustness of material selection decisions. In: 2009. IEEE International Symposium on Sustainable Systems and Technology

Optis M, Wild P (2010) Inadequate documentation in published life cycle energy reports on buildings. Int J Life Cycle Assess 15:644-651

Ortiz O, Castells F, Sonnemann G (2009) Sustainability in the construction industry: a review of recent developments based on LCA. Constr Build Mater 23:28-39

Passer A, Kreiner H, Maydl P (2012) Assessment of the environmental performance of buildings: a critical evaluation of the influence of 
technical building equipment on residential buildings. Int J Life Cycle Assess 17:1116-1130

PE International (2014) Harmonization of LCA methodologies for metals. (PE International, Ottawa, 2014) https://www.icmm.com/ document/6657

Preservation Green Lab (2012) The greenest building: quantifying the environmental value of building reuse. Report, national trust for historic preservation. http://www.preservationnation.org/ information-center/sustainable-communities/green-lab/lca/The Greenest_Building_lowres.pdf

Puga H, Barbosa J, Soares D, Silva F, Ribeiro S (2009) Recycling of aluminium swarf by direct incorporation in aluminium melts. J Mater Process Technol 209(11):5195-5203

Rombach G (2013) Raw material supply by aluminium recycling - efficiency evaluation and long-term availability. Acta Mater 61(3): $1012-1020$

RSMeans (2014) Facilities maintenance and repair cost data 2014. Mossman NJ, Plotner SC (eds) Kingston, MA: RSMeans

Salazar J, Sowlati T (2008) A review of life-cycle assessment of windows. For Prod J 10(58):91-96

Schlesinger ME (2013) Aluminum recycling. CRC Press, London

Simonen K (2014) Life cycle assessment. Pocket Architecture Technical Series London, Routledge
Sinha A, Kutnar A (2012) Carbon footprint versus performance of aluminum, plastic, and wood window frames from cradle to gate. Buildings 2:542-553

US Department of Energy (2010). 2009 Buildings Energy Data Book. Washington D.C

US EPA (2009) Estimating 2003 building-related construction and demolition material amounts. US environmental protection agency report. http://www.epa.gov/wastes/conserve/imr/cdm/pubs/cd-meas.pdf

VinylPlus (2014) 2014 Progress Report.www.vinylplus.eu/uploads/ Modules/Bannersreport/vinylplus-pr2014_en.pdf

Wardenaar T, van Ruijven T, Mendoza Beltran A, Vad K, Guinée J, Heijungs R (2012) Differences between LCA for analysis and LCA for policy: a case study on the consequences of allocation choices in bio-energy policies. Int J Life Cycle Assess 17(8): 1059-1067

Weidema BP, Bauer CH, Hischier R, Mutel CH, Nemecek T, Reinhard J, Vadenbo CO, Wernet G (2013) The Ecoinvent database: overview and methodology, data quality guideline for the ecoinvent database version 3. www.ecoinvent.org

Werner F, Richter K (2000) Economic allocation in LCA: a case study about aluminium window frames. Int J Life Cycle Assess 5(2):7983 